\title{
Article
}

\section{Trends in Emission Inventory of Marine Traffic for Port of Haifa}

Elyakim BenHakoun ${ }^{1}$, Eddy Van De Voorde ${ }^{2}$, Yoram Shiftan ${ }^{1}$

${ }^{1}$ The Technion - Israel Institute of Technology, Haifa, Israel - ebh@technion.ac.i1, shiftan@technion.ac.il

${ }^{2}$ The University of Antwerp - Belgium, Antwerp, Belgium, eddy.vandevoorde@uantwerpen.be * Correspondence: ebh@technion.ac.il

\section{Abstract}

This research investigates Haifa ports emissions' contribution to the existing daily emission inventory level in the area. This research based on developed full bottom-up model framework that looks at the single vessel daily voyage through its port call stages. The main data sources for vessels movements used in this research are the Israel Navy`s movements log and Israel Administration of Shipping and Ports' (ASP) operational vessel movements and cargo log. The Fuel Consumption (FC) data and Sulfur Content (SC) levels are based on an official Israel ASP survey data. Observation years in this research are 2010 - 2018 with focus on the Ocean-Going Vessels (OGV) type only. The results show that the vessel fleet calling at Israel ports is mainly vessels that have a lower engine Tier grade (i.e., Tier 0 and 1) which is considered a heavy contributor to Nitrogen Oxides (NOx) pollutant. The study recommends on an additional cost charged (selective tariff) to reflect the external social cost linked to the single vessel air pollution combined with supportive technological infrastructure and economic incentive tools (e.g. electric subsidy) to attract or influence vessel owners to assign vessels equipped with new engine Tier grades for calls at Israeli ports.

Keywords: The Daily Port Emission Inventory, Big Data, Selective Tariff, Haifa Port Emission Inventory

\section{Introduction}

This study investigated and developed a generic full bottom-up model framework that looks at the single vessel voyage through its port call stages. Two main data sources were used in this study. The first data source is the Israel Navy`s movements log and the second data source is the Israel Administration of Shipping and Ports (ASP)'s operational vessel movements and cargo $\log$. The years of observation are 2010-2018 with focus on the Ocean-Going Vessels (OGV) type only. This model was used to estimate the daily port emission inventory for Haifa \& Ashdod (with Ashkelon) and for vessel movements across the Israel shoreline. "Big data" analytics with SQL queries techniques were used to deal with the analysis process, where advance data mining methods with Python queries were used to complete missing technical information from known maritime professional sites.

\subsection{Aims and Objectives}

This study aims to provide decision makers valuable information concerning emissions arising from OGV movements in the port area.

- Identify the constraints to be overcome in order to prevent "pollution haven" or "pollution leakage" to mainland.

- Provide estimates and identify the port's share of contribution compared to other main pollutant emitters in the area. 
The emission results reported, can then be used for air quality analysis and the development of recommended marine emission reduction policy as well as recommended emission reduction targets for each vessel category type and category class.

\subsection{Scope of Study}

The generic port emission inventory model targets only Ocean-Going Vessels (OGV), thus excluding all marine traffic of private yacht, domestic vessels movements (tugs, navy, fishing, service vessels, etc.), trucks (heavy or light), trains or any machinery/equipment emissions that were operated in the port jurisdiction area in the calendar years noted.

The scope of this research for the study case will look at Haifa port one of Israel's main ports. The Haifa emission inventory analysis includes all the vessel traffic in Haifa port and in the Israel Shipyards' port (currently the only private port in Israel). This decision to aggregate was made due to the proximity of the two ports and which cannot be overlooked.

The exhaust emissions of the following pollutants were estimated in this study:

- Common Air Contaminants (CAC)s - SOx, NOx, CO, HC and total Particulate matter (PM) (10-micron and 2.5-micron)

- Greenhouse Gases (GHGs) - $\mathrm{CO}_{2}$

\subsubsection{Key Assumptions}

- The AE and boilers were considered to be sharing the same fuel type, as no legislative action were required otherwise and operation using the same fuel type is economically justified.

- Sulfur levels were on Israel ASP FC survey and are assumed to be consistent for this study calendar years 2010-2018 in order to provide a conservative estimate, although a rate of $4.5 \%$ of Sulfur content was a possibility for years 2010 and 2011.

- The FC factors figures for vessel port time is based on ASP FC survey records, thus providing a concrete low-bound estimation for emissions arising from vessel activity at port and portrelated area. This estimation is lacking FC figures concerning the "full away" stage and sailing in and out the port area. Nevertheless, these stages are considered insignificant in terms of FC compared to vessel port time FC performance.

\subsection{Israel Ports}

Israel seaports are responsible for more than $99 \%$ of Israel international trade in terms of export and import and around $80 \%$ in terms of value ${ }^{1}$. Israel's main international trade ports are Haifa and Ashdod, as illustrated in Figure 2. All Israel ports are all currently public owned port companies except for the Haifa - Israel Shipyard company port and Eilat Port that are privately owned. In this research, the Haifa port case study is present in details to demonstrate the model capabilities.

\subsubsection{Haifa Port}

The Port of Haifa was constructed in 1933, by the British Empire. Since 1948, it has been rebuilt and developed by the Israeli government. Haifa Port serves as one of the two main significant ports and economic bridge of Israel with the outside world. During 2010, under the port expansion program, it was resolved to open a new container terminal. The new Carmel Port dock provides an additional $700 \mathrm{~m}$ of quayage with a depth of 15.8 meters which is capable of handling up to $14 \mathrm{~K}$ TEU size container vessels ${ }^{2}$. A later expansion program is now underway and is expected complete construction of a newer container terminal. The HaMifratz Port dock, which

\footnotetext{
${ }^{1}$ Maritime Policy for Israel's Mediterranean Waters 2018 -

https://www.gov.il/BlobFolder/generalpage/policy maritime/he/Water Energy Communication merhav yami_english v5.pdf, - Retrieved November 21th 2019.

2 Haifa port - https://www.haifaport.co.il/wp-content/uploads/2019/05/booklet-en.pdf - Retrieved November 21 th 2019.
} 
is scheduled to open in 2021, will have with additional $800 \mathrm{~m}$ of quayage with depth of 17.3 meters, which will be capable of handling up to $15 \mathrm{~K}$ TEU size container vessels. Haifa Port includes Container, Bulk and General Cargo (i.e. breakbulk), Cruise and Oil / Liquid (included chemical) terminals.

Haifa Port is located in a high-altitude terrain topography that surrounds the Haifa Bay area. The dominant wind direction is North West to the South East, while in the summer the dominant wind direction shifts to South West to North West (LEVIN et al., 2012b), as illustrated in Figure 1.
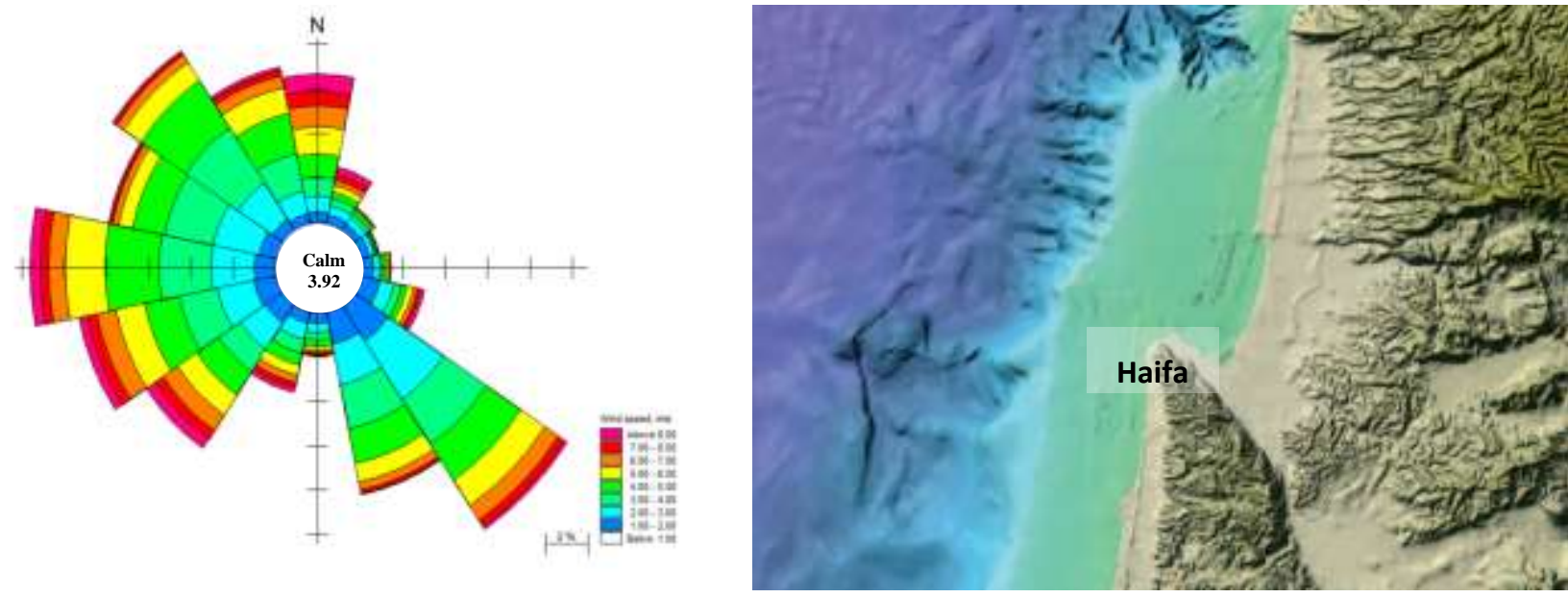

Figure 1: Wind Rose Diagram Based on 9 Years of 10 Min Averaged Wind Observation at Haifa Source: Wind Rose - CAMERI report PN 736 (LEVIN et al., 2012b), Haifa bay - Shaded Relief Map - Hall, K.K \& Calvo R. 2005.

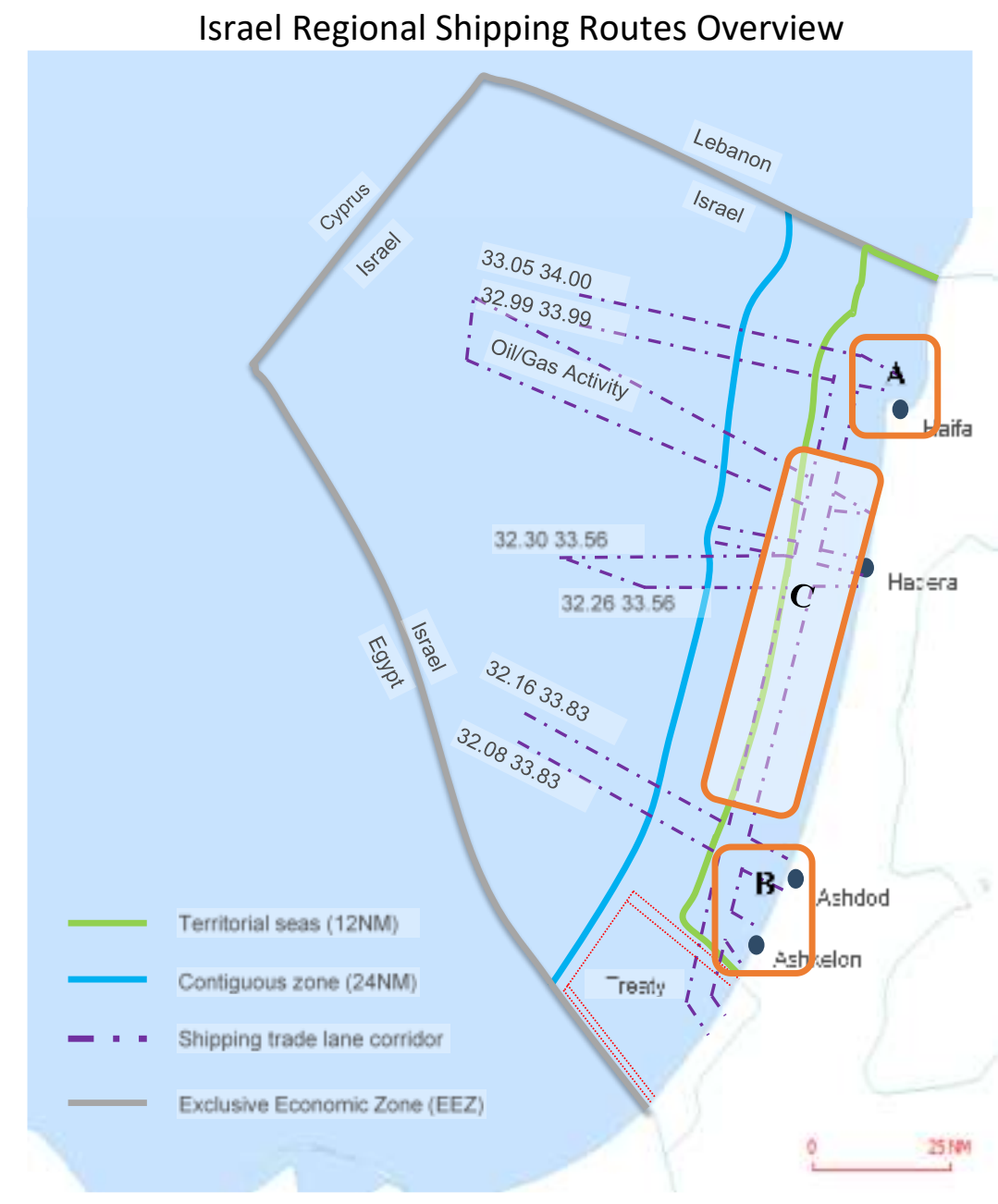

Figure 2: Israel Maritime Boundary Map Relative to Regional Shipping Routes

Source: Own composition, based on CSA Ocean Sciences Inc. 2016; Institute 2016 and Israel Navy data. 


\subsection{Claims and Contributions}

This study claims that vessels' contribution to local emission inventory can't be overlooked since this study makes the analogy that each vessel should be treated as a "Floating Industrial Plant" and should be treated in terms of emissions as a land-based plant. This study claims, that emissions arising from both a land-based plant with a small and/or mid and/or high dynamic emission level contribution and emissions arising from vessels in port and port related areas, should be managed at high level overview, since they both can be considered heavy industrial pollution zones in terms of daily, monthly and yearly emission level.

This study claims that on certain days, emissions arising from the port area exceed even the daily industrial zone limits. This study makes an analogous claim that each area should be examined and managed as a collection of "flue gas stacks" as shown in Figure 3. In addition, this study claims that due to the height of the flue gas stacks onboard vessels which are significantly lower compared to flue gas stacks installed in land-based plants, they may affect area air quality significantly more than the industrial zone. The latter are usually subject to extensive environmental emission regulations compared to vessels in port.
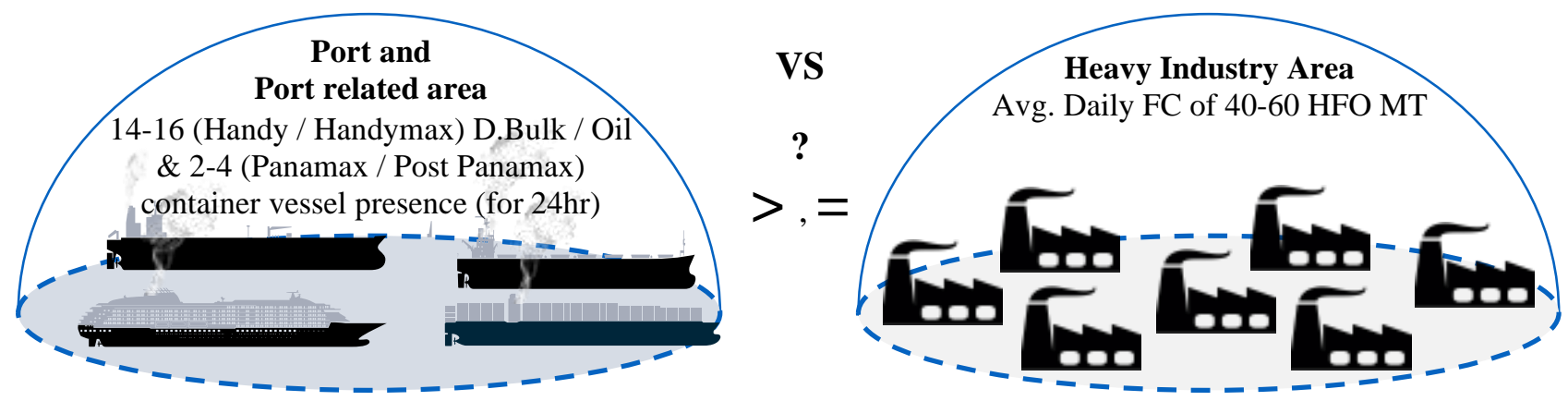

Figure 3: Emission Level Conribution, Vessels Presences at Port Area vs. Heavy Industy Area.

Source: Own composition.

The results gained from this study can serve as a decision support tool, for decision makers' assessment of the single vessel's contribution to the emission level in port and port related area worldwide. Thus, allowing ports worldwide to identify the main pollution contributors, based on a daily FC and emission calculation performance. This study model framework has the potential to promote green sea freight transportation while trying to prevent the "pollution leakage" phenomena (i.e. transshipment of sea freight cargo to land transportation means).

\subsection{The Study Structure}

The following sections present the Model Input Data section explains and specifies key variables and assumptions used for the Haifa port emission inventory model. The daily emission inventory estimations results are presented in the Results section. The last section concludes with a summary review, policy recommendation. 


\section{Methodology}

This study will present the methodology procedure and the material analysis in logical order as described in Figure 4. The following case study present an in-depth analysis of Haifa Port Emission Inventory based on daily port and shoreline Emission Inventory Model [4]. "Big data" analytics with SQL queries techniques were used to deal with the analysis process examine the daily emission levels, segmentized by OGVs category type and class for pollutant contributors' analysis.

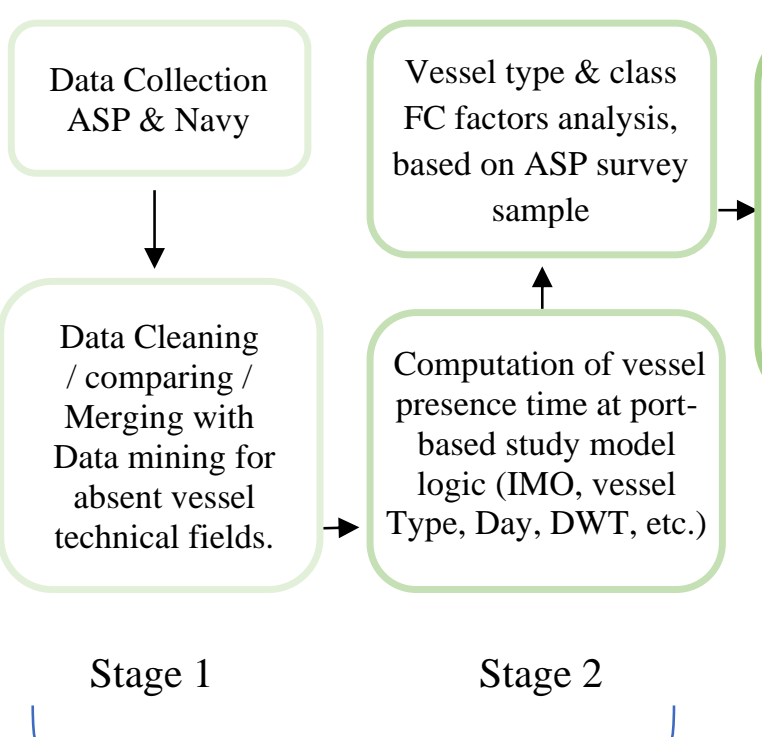

Phase I

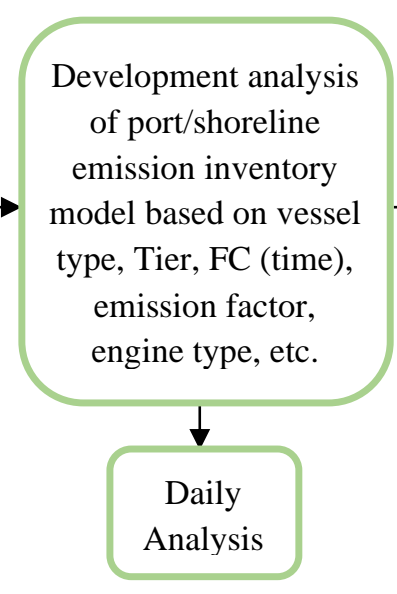

Stage 3

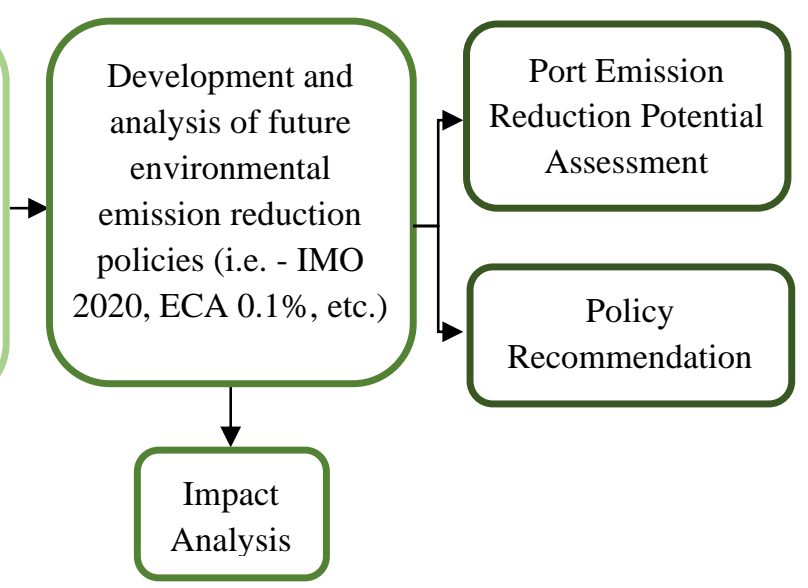

Stage 4

Stage 5

Phase II All vessels in this study were categorized by type of cargo based on IMO $3^{\text {rd }}$ GHG study logic. The international merchant vessels fleet varies in cargo designation, capacity classification and physical size. In order, to maintain consistency, this study follows the IMO Third GHG report guideline and aggregates vessel category type according to the cargo carrying designation [5].

\subsection{Model Emission Factors and Engine Assumptions}

The emissions calculation methodology is based on the multiplication of an EF for each GHG and CAC emission with FC (with specific consumption factor). The results are then totaled for each type of vessel, class, fuel and engine type in use for a daily analysis.

The emissions reported in this study, are based on ASP FC figures taken from the ASP survey per each type and class of vessel. The following section presents the latest known EF existing today and acknowledged by IMO, EPA and the EU.

\subsubsection{Emission Factors}

The main emission factors used in this study are based on EFs reported in the Third IMO GHG Study, ENTEC 2002/2005/2007/2019 Studies, IVL Swedish Environmental Research Institute 2004 Study and HOK Marine consult ApS 2015 Study. Most of EFs reported in these studies are based on the Carlton et al. 1995 analysis study commonly known in the literature as the Lloyd's Register 1995 Study.

\subsubsection{SFOC}

In general, the EFs reported and cited in these studies are presented in g pollutant $/ \mathrm{kWh}$ units and were therefore converted to a fuel-based EF by dividing by Specific Fuel Oil Consumption (SFOC), which is presented in $\mathrm{g}$ pollutant $/ \mathrm{g}$ fuel or $\mathrm{kg}$ units. Each related SFOC was corresponded to each related fuel and engine type associated with its related EFs. 
The following Equation 1 was used to convert energy-baseline EFs in g pollutant $/ \mathrm{kWh}$ to fuelbased emissions factors in $\mathrm{g}$ pollutant/g fuel consumed emissions factors for the port inventory study.

1

$$
E F_{\text {base }}=\frac{E F_{\text {base }}((g \text { pollutant }) / k W h)}{E F_{\text {base }}((g \text { fuel }) / k W h)}
$$

The SFOCs were derived from the IVL Study as reported in IMO`s last GHG report. The IVL study on SFOCs based its analysis on EF reported in the ENTEC 2002 Study that are also used in this study. [6]-[13].

\subsubsection{Baseline Emissions factors}

The baseline EFs used in this study are used for both for AE and boilers FC (with further justification for fuel type and engine rate in use per each vessel), whether the vessel engines were found to be pre-IMO Tier I (i.e. Tier 0) or Tier I standard or if they meet IMO Tier II or Tier III standard requirements. The vessel engine configuration, fuel type and SC assumptions used in the study are presented in Table 1 and

Table $2[6]-[13]$.

PM EFs, reported and cited in literature, vary significantly between studies depending on each practice used. Nevertheless, for SOx EFs there is a consensus for EFs reported based on the analysis of the Lloyd's Register 1995 study as show in the following equations which were used to develop the baseline and actual emission factors for the port inventory study, as presented below in equations 2,3,4,5,6, 7 and as present in Table 1 [6].

Both PM and SOx EFs are affected by the level of percentage of Sulfur content existing in fuel. In order to provide a conservative figure, the reported PM EFs (with \% SC adjusted) as reported in the Third IMO GHG Study, were not chosen as they present high EFs number or were considered not current compared to new studies in the field. Therefore, PM EFs for auxiliary engines were derived from the EMEP/CORINAIR 2007 as reported in the HOK Marine consult ApS 2015 study, as shown in Equation 6, and 7 and presented in Table 1 [5], [13], [14].

Table 1: Baseline Emission Factors

\begin{tabular}{|c|c|c|c|c|c|c|c|c|c|c|c|c|c|}
\hline & & $\begin{array}{l}\text { Engine } \\
\text { Type }\end{array}$ & $\begin{array}{c}\text { Speed } \\
\text { Rate }\end{array}$ & $\begin{array}{l}\text { Fuel } \\
\text { Type }\end{array}$ & Unit & Engine & $\begin{array}{c}\text { Study } \\
\text { EF }\end{array}$ & $\begin{array}{c}\text { Study } \\
\text { EF } \\
\text { Source }\end{array}$ & $\begin{array}{c}\text { IMO } \\
\text { EF }\end{array}$ & $\begin{array}{l}\text { IMO EF } \\
\text { Source }\end{array}$ & $\#$ & $\begin{array}{c}\mathbf{E q} \\
\cdot\end{array}$ & $\begin{array}{l}n \text { for } \\
\text { NOx }\end{array}$ \\
\hline \multirow{2}{*}{\multicolumn{2}{|c|}{$\mathrm{CO}_{2}$ emission }} & $\begin{array}{l}\text { 2-Stroke / } \\
\text { 4-Stroke }\end{array}$ & $\begin{array}{l}\mathrm{SSD} / \\
\mathrm{MSD} / \\
\mathrm{HSD}\end{array}$ & $\mathrm{HFO}$ & $\mathrm{g} / \mathrm{kg}$ fuel & $\begin{array}{l}\mathrm{AE} / \\
\mathrm{ME}\end{array}$ & 3,114 & $\begin{array}{c}\text { MEPC } \\
62 \text { / 23, } \\
\text { Annex } 8\end{array}$ & 3,114 & $\begin{array}{c}\text { MEPC } \\
\text { 62/23, } \\
\text { Annex } 8\end{array}$ & & 2 & \\
\hline & & $\begin{array}{l}\text { 2-Stroke / } \\
\text { 4-Stroke }\end{array}$ & $\begin{array}{c}\mathrm{SSD} / \\
\mathrm{MSD} / \\
\mathrm{HSD}\end{array}$ & MGO & $\mathrm{g} / \mathrm{kg}$ fuel & $\begin{array}{l}\mathrm{AE} / \\
\mathrm{ME}\end{array}$ & 3,206 & $\begin{array}{c}\text { MEPC } \\
62 \text { / 23, } \\
\text { Annex } 8 \\
\end{array}$ & 3,206 & $\begin{array}{c}\text { MEPC } \\
62 / 23, \\
\text { Annex } 8 \\
\end{array}$ & & 2 & \\
\hline \multicolumn{2}{|c|}{ CO emission } & 2-Stroke & $\begin{array}{c}\mathrm{SSD} / \\
\mathrm{MSD} / \\
\mathrm{HSD}\end{array}$ & $\begin{array}{l}\mathrm{HFO} / \\
\mathrm{MGO}\end{array}$ & $\mathrm{g} / \mathrm{kWh}$ & $\begin{array}{l}\mathrm{AE} / \\
\mathrm{ME}\end{array}$ & 0.35 & $\begin{array}{c}\text { Lloyd's } \\
\text { Register } \\
(1995)\end{array}$ & 0.54 & $\begin{array}{c}\text { Sarvi et al. } \\
2008\end{array}$ & & 3 & \\
\hline \multicolumn{2}{|c|}{ HC emission } & $\begin{array}{l}\text { 2-Stroke / } \\
\text { 4-Stroke }\end{array}$ & $\begin{array}{l}\mathrm{SSD} / \\
\mathrm{MSD} / \\
\mathrm{HSD}\end{array}$ & $\begin{array}{l}\mathrm{HFO} / \\
\mathrm{MGO}\end{array}$ & $\mathrm{g} / \mathrm{kWh}$ & $\begin{array}{l}\mathrm{AE} / \\
\mathrm{ME}\end{array}$ & 0.5 & $\begin{array}{c}\text { Lloyd's } \\
\text { Register } \\
(1995)\end{array}$ & 0.5 & $\begin{array}{c}\text { Cooper } \\
\text { and } \\
\text { Gustafsson } \\
(2004)\end{array}$ & & 4 & \\
\hline \multirow{6}{*}{$\begin{array}{c}\text { NOx } \\
\text { emission }\end{array}$} & Tier 0 & 2-Stroke & SSD & $\begin{array}{l}\mathrm{HFO} / \\
\mathrm{MGO}\end{array}$ & $\mathrm{g} / \mathrm{kWh}$ & $\mathrm{ME}$ & 19.8 & $\begin{array}{l}\text { IVL, } \\
2004\end{array}$ & 18.1 & $\begin{array}{l}\text { Entec } \\
2002\end{array}$ & & 5 & $\begin{array}{c}\mathrm{n}= \\
\sim 130\end{array}$ \\
\hline & Tier I & 2-Stroke & SSD & $\begin{array}{l}\mathrm{HFO} / \\
\mathrm{MGO}\end{array}$ & $\mathrm{g} / \mathrm{kWh}$ & $\mathrm{ME}$ & 17 & $\begin{array}{c}\text { IMO } \\
\text { Standard }\end{array}$ & $\mathrm{n} / \mathrm{a}$ & $\begin{array}{c}\text { Smith et al. } \\
2014\end{array}$ & $*$ & 5 & $\begin{array}{c}\mathrm{n}= \\
\sim 130\end{array}$ \\
\hline & Tier II & 2-Stroke & SSD & $\begin{array}{l}\mathrm{HFO} / \\
\mathrm{MGO}\end{array}$ & $\mathrm{g} / \mathrm{kWh}$ & ME & 14.4 & $\begin{array}{c}\text { IMO } \\
\text { Standard }\end{array}$ & $\mathrm{n} / \mathrm{a}$ & $\begin{array}{c}\text { Smith et al. } \\
2014\end{array}$ & $*$ & 5 & $\begin{array}{c}\mathrm{n}= \\
\sim 130\end{array}$ \\
\hline & Tier III & 2-Stroke & SSD & $\begin{array}{l}\mathrm{HFO} / \\
\mathrm{MGO} \\
\end{array}$ & $\mathrm{g} / \mathrm{kWh}$ & ME & 3.4 & $\begin{array}{c}\text { IMO } \\
\text { Standard }\end{array}$ & $\mathrm{n} / \mathrm{a}$ & $\begin{array}{c}\text { Smith et al. } \\
2014\end{array}$ & & 5 & $\begin{array}{c}\mathrm{n}= \\
\sim 130\end{array}$ \\
\hline & Tier 0 & 4-Stroke & $\begin{array}{l}\text { MSD/ } \\
\text { HSD }\end{array}$ & $\begin{array}{l}\mathrm{HFO} / \\
\mathrm{MGO}\end{array}$ & $\mathrm{g} / \mathrm{kWh}$ & $\mathrm{AE}$ & 14.2 & $\begin{array}{l}\text { IVL, } \\
2004\end{array}$ & 13.2 & $\begin{array}{c}\text { Smith et al. } \\
2014\end{array}$ & $* *$ & 5 & $\begin{array}{c}\mathrm{n}= \\
\sim 745\end{array}$ \\
\hline & Tier I & 4-Stroke & $\begin{array}{l}\text { MSD/ } \\
\text { HSD }\end{array}$ & $\begin{array}{l}\mathrm{HFO} / \\
\mathrm{MGO}\end{array}$ & $\mathrm{g} / \mathrm{kWh}$ & $\mathrm{AE}$ & 11.7 & $\begin{array}{c}\text { IMO } \\
\text { Standard }\end{array}$ & 11.7 & $\begin{array}{c}\text { Smith et al. } \\
2014\end{array}$ & $* *$ & 5 & $\begin{array}{c}\mathrm{n}= \\
\sim 745\end{array}$ \\
\hline
\end{tabular}




\begin{tabular}{|c|c|c|c|c|c|c|c|c|c|c|c|c|}
\hline Tier II & 4-Stroke & $\begin{array}{l}\text { MSD/ } \\
\text { HSD }\end{array}$ & $\begin{array}{l}\mathrm{HFO} / \\
\mathrm{MGO}\end{array}$ & $\mathrm{g} / \mathrm{kWh}$ & $\mathrm{AE}$ & 9.6 & $\begin{array}{c}\text { IMO } \\
\text { Standard }\end{array}$ & 9.7 & $\begin{array}{c}\text { Smith et al. } \\
2014\end{array}$ & $* *$ & 5 & $\begin{array}{c}\mathrm{n}= \\
\sim 745\end{array}$ \\
\hline Tier III & 4-Stroke & $\begin{array}{c}\text { MSD/ } \\
\text { HSD }\end{array}$ & $\begin{array}{l}\mathrm{HFO} / \\
\mathrm{MGO} \\
\end{array}$ & $\mathrm{g} / \mathrm{kWh}$ & $\mathrm{AE}$ & 2.4 & $\begin{array}{c}\text { IMO } \\
\text { Standard }\end{array}$ & $\mathrm{n} / \mathrm{a}$ & & $*$ & 5 & $\begin{array}{c}\mathrm{n}= \\
\sim 745 \\
\end{array}$ \\
\hline $\mathrm{SO}_{2}$ emission & $\begin{array}{c}\text { 2-Stroke / } \\
\text { 4-Stroke }\end{array}$ & $\begin{array}{c}\mathrm{SSD} / \\
\mathrm{MSD} / \\
\mathrm{HSD} \\
\end{array}$ & $\begin{array}{l}\mathrm{HFO} / \\
\mathrm{MGO}\end{array}$ & $\mathrm{g} / \mathrm{kWh}$ & $\begin{array}{l}\mathrm{AE} / \\
\mathrm{ME}\end{array}$ & $20 * \mathrm{SC}$ & $\begin{array}{c}\text { Lloyd's } \\
\text { Register } \\
(1995)\end{array}$ & $20 * \mathrm{SC}$ & $\begin{array}{c}\text { Lloyd's } \\
\text { Register } \\
(1995) \\
\end{array}$ & & 6 & \\
\hline PM emission & $\begin{array}{c}\text { 2-Stroke / } \\
\text { 4-Stroke }\end{array}$ & $\begin{array}{c}\mathrm{SSD} / \\
\mathrm{MSD} / \\
\mathrm{HSD}\end{array}$ & $\begin{array}{l}\mathrm{HFO} / \\
\mathrm{MGO}\end{array}$ & $\mathrm{g} / \mathrm{kWh}$ & $\begin{array}{l}\mathrm{AE} / \\
\mathrm{ME}\end{array}$ & Eq 6 & $\begin{array}{c}\text { EMEP/C } \\
\text { ORINAIR } \\
2009\end{array}$ & $\begin{array}{c}0.854 * \mathrm{EX} \\
\mathrm{P}(\mathrm{SC} \% * 0 . \\
745)\end{array}$ & EPA 2007 & & 7 & \\
\hline
\end{tabular}

The following equations were used to develop the baseline and actual emissions factors for the port inventory study, as presented below:

2: $C O_{2}^{E F}=E F \cdot F C$

3: $C O^{E F}=E F \cdot(S F O C)^{-1} \cdot F C$

4: $H C^{E F}=E F \cdot(S F O C)^{-1} \cdot F C$

5: $N O x^{E F}=E F(\mid$ Tier $) \cdot(S F O C)^{-1} \cdot F C$

6: $S O_{2}^{E F}=20 \cdot S C(\mid$ Calorific value $)$

7: $P M^{E F}=0.26+0.081 \cdot S C+0.103 \cdot S C^{2}$

Note: * - 4-stroke - Tier 0 - 18.1 for ME, Tier I - 17 for ME, Tier II - Based on average of 15.3 (SSD) and 11.2 (MSD)

Note: ** - 4-stroke - Tier 0 - Average of 14.7 (MSD) and 11.6 (HSD), Tier 1 - Average of 13.0 (MSD) and 10.7 (HSD), Tier 2 - Average of 13.0 (MSD) and 10.7 (HSD)

\subsubsection{Vessel Engine, Fuel Type and S.C Assumptions per Vessel Category}

Vessel engines are designed around the fuels they are planned to burn. The OGV engines are usually considered high consumers of energy, therefore vessel owners usually face two main alternatives while selecting the main propulsion machinery during shipyard construction: 2Stroke or 4-Stroke engine. In the maritime industry, for OGV the 2-Stroke engine is more commonly used as ME while the 4-Stroke engine is more commonly used for an auxiliary engine. Boilers are mainly considered as an onboard heat production unit and so consume energy but do not produce energy [7], [12]. An OGV can be installed with two or more auxiliary engines to support it energy needs while at port/hotelling (i.e. 4-Stroke), where OGV can be installed with up to two ME depending on vessel size [7], [18].

Both the 2-Stroke and 4-Stroke engines allow the use of RM and DM from low-grade fuel oil. A 2-Stroke combustion engine which is fueled with RM fuel, will present a higher efficiency performance compared to a 4-Stroke engine combustion engine [7], [18]. The 2-Stroke engine's massive size allows it to operate as an "Omnivore" engine, as it can accept any existing material in nature with some energy factor and transpose it to raw energy.

The Cruise ships require high maneuvering performance since they operate close to residential areas and frequently change passengers. This sensitive issue led vessel owners in this sector to operate on two main configurations of engine. The first one is the full Diesel-Electric (DE) engine, typically in used in Cruise, Passenger and Ferry vessels. These vessels can be fueled with DM or RM fuel although they are typically fueled with DM fuel with a SC of less than $1.5 \%$ depending on the regulations under which they operate. The second configuration is a geared shaft configuration where the ME and the auxiliary diesel-electric engines are used for different energy efforts [19]. 
To summarize, the vessel engine configuration, fuel type and SC assumptions used in the study are presented in

Table 2.

Table 2: Vessel Engine, Fuel Type and S.C per Vessel Category Type Assumption

\begin{tabular}{|c|c|c|c|c|c|c|c|}
\hline \multirow{2}{*}{$\begin{array}{c}\text { Vessel Category } \\
\text { Type }\end{array}$} & \multicolumn{3}{|c|}{ High Sea (ME) } & \multicolumn{3}{|c|}{$\operatorname{Port}(A E)$} & \multirow[b]{2}{*}{ S.C } \\
\hline & $\begin{array}{c}\text { Engine } \\
\text { Speed } \\
\text { Design } \\
\end{array}$ & $\begin{array}{c}\text { Engine } \\
\text { Type }\end{array}$ & $\begin{array}{l}\text { Fuel } \\
\text { Type }\end{array}$ & $\begin{array}{c}\text { Engine } \\
\text { Speed } \\
\text { Design } \\
\end{array}$ & $\begin{array}{c}\text { Engine } \\
\text { Type }\end{array}$ & Fuel Type & \\
\hline Container & SSD & 2-Stroke & $\mathrm{HFO}$ & MSD/HSD & 4-Stroke & $\mathrm{HFO}$ & $2.48 \%$ \\
\hline General Cargo & SSD & 2-Stroke & $\mathrm{HFO}$ & MSD/HSD & 4-Stroke & $\mathrm{HFO}$ & $2.48 \%$ \\
\hline Chemical Tanker & SSD & 2-Stroke & $\mathrm{HFO}$ & MSD/HSD & 4-Stroke & $\mathrm{HFO}$ & $2.48 \%$ \\
\hline Oil Tanker & SSD & 2-Stroke & $\mathrm{HFO}$ & MSD/HSD & 4-Stroke & $\mathrm{HFO}$ & $2.48 \%$ \\
\hline Bulk Carrier & SSD & 2-Stroke & $\mathrm{HFO}$ & MSD/HSD & 4-Stroke & $\mathrm{HFO}$ & $2.48 \%$ \\
\hline$R o-R o$ & SSD & 2-Stroke & HFO & MSD/HSD & 4-Stroke & $\mathrm{HFO}$ & $2.48 \%$ \\
\hline Cruise/Passenger & MSD/HSD & $\mathrm{DE}$ & MGO & MSD/HSD & $\mathrm{DE}$ & MGO & $1 \%$ \\
\hline TSHD Dreger & MSD/HSD & 4-Stroke & $\mathrm{HFO}$ & MSD/HSD & 4-Stroke & HFO & $3 \%$ \\
\hline Dreger (small) & MSD/HSD & 4-Stroke & MGO & MSD/HSD & 4-Stroke & MGO & $0.1 \%$ \\
\hline
\end{tabular}

\subsection{Model Implications - Israel Ports - Case Studies}

The following sections will present the implications of the Port Emission Inventory Model Framework for Israel's main ports. Each section presents a description and background data inputs and explains key variables and assumptions used for each relevant case study that lay the foundations for the model's implications for Israel's ports.

\subsubsection{Israel Maritime Transportation - In Numbers}

The primary source of data for the Israel ports study is based on Israel Navy and Israel ASP records. The Israel Navy and ASP databases provide crucial information for the bottom-up approach. Cross matching queries were carried to validate and ensure and the credibility of these datasets and this study.

Container vessels are the dominant vessel in the ports in terms of visit call, followed by general cargo and oil tankers as shown in Figure 5. From the analysis, a decreasing in visit trend can be seen for containers and general cargo for both ports, and an increasing visit trend for bulk carriers for both port. However, this trend phenomena cannot teach us anything yet as total cargo (Tons) by vessels class size analysis is absent at this stage. 


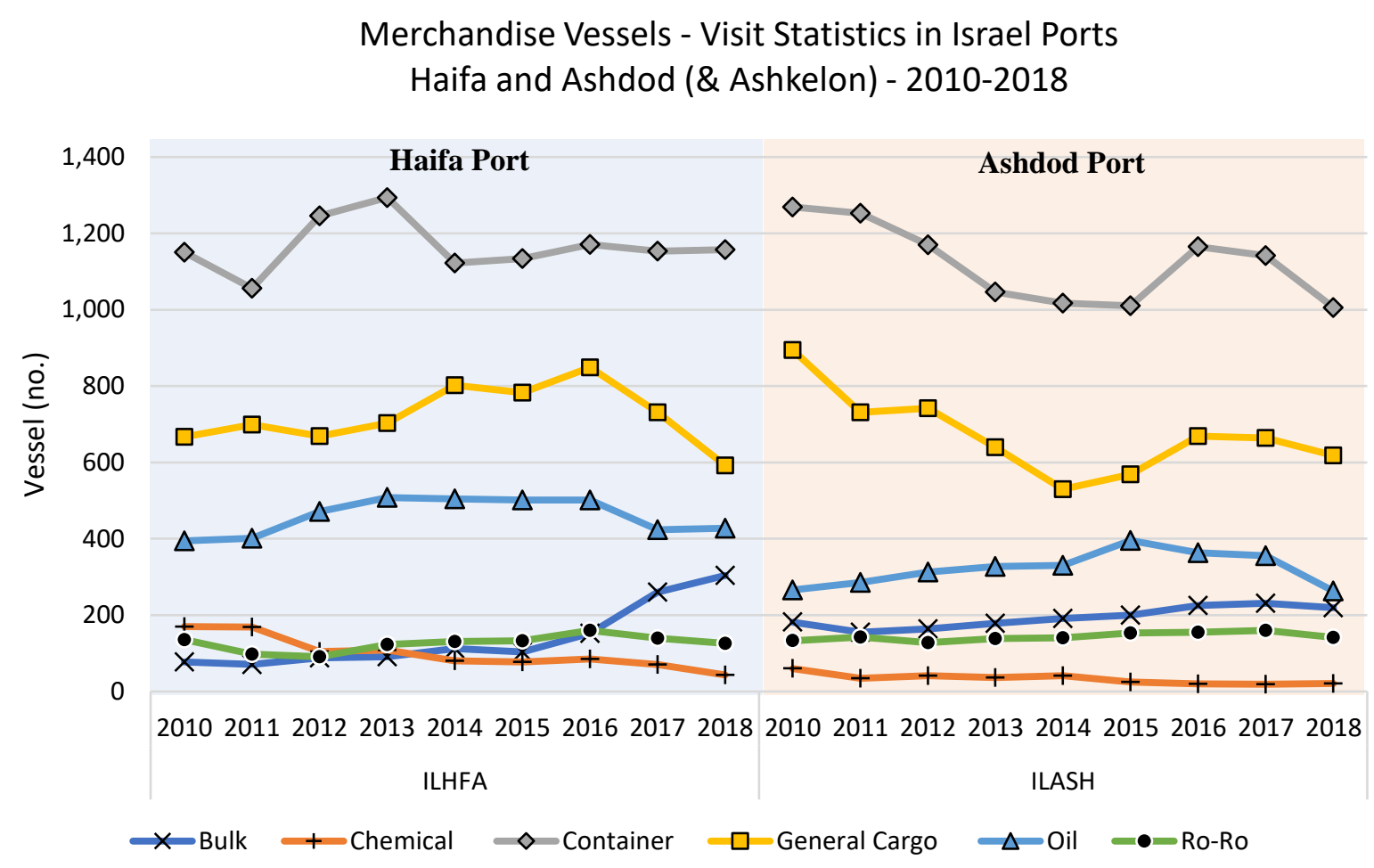

Figure 5: Vessel Visit by Category - Haifa and Ashdod - Trend Analysis - Years 2010-2018 Source: Own composition, based on study logic (includes vessel at anchorage visits).

\subsubsection{Israel Port - Fuel Type in Use}

HFO is the most commonly used fuel in Israel ports. This assumption is logical and economically wise for all vessels within ports as Israel does not have a local set of limitations for SC in bunker fuels, since Israel's current policy is to be in line with IMO global regulation. Yet, to strengthen this assumption, the data samples of the FC survey was analyzed by fuel type for ME, AE and boilers, thereby removing any uncertainty in the model for this issue. As expected, findings show that HFO was the most common fuel in use for OGV vessels within Israeli ports for both ME, $\mathrm{AE}$ and boilers alike.

\subsubsection{Accuracy and Reliability}

Vessels movement data and FC data are the pillars of the port and shoreline emission inventory model frameworks. The strength of the first pillar, vessel movement data, relies on the fact that it comes from official sources. The Israeli Navy and the Israeli ASP are two different entities with separate and different methods for collecting and documenting vessel movements within Israel. Nevertheless, the accuracy of the datasets received from the Israel Navy and Israel ASP, is considered extremely high, as both serve as "watch dogs" for maritime movements.

The strength of the second pillar, FC data, relies on the fact that the data comes from an official survey conducted by the ASP Department of Supervision and Control. All FC figures in this study were validated by recognized professional sources. 


\section{Model Results}

\subsection{Port Emission Inventory and Maritime Transportation (Freight and Fleet) Trend Effect}

While examining the emission inventory in ports and its magnitude in relation to the maritime transportation in Israeli ports, this study assumed that segmentation of each category of vessel to class could play a significant role in the calculation of port emission inventory. This factor could reflect changes in both freight, fleet size and emission trends. Therefore, this study addressed the selected period of 2010-2018, an indication of port emission trends, vessel category/class with Tier analysis for each type of GHG and CAC emissions as described above.

\subsubsection{Fleet Call Israel Ports}

Findings from the Port Emission Inventory Model framework shows that between 2010-2018, the 5,360 of unique vessels of the merchandise fleet called at Israel's main ports. This fleet is dominated by Tier 0 and Tier 1 engine grade, $36 \%$ and $48 \%$ respectively, where Tier 2 and 3 totals $16 \%$, as can be seen in Figure 6 . These findings are based on the analysis of vessels' technical characteristics and year of manufacture.

Analysis of the Israel Navy and ASP datasets' classification processes for the actual and predictive vessel size for this model framework, made it possible to segment the current fleet into different categories type and into different of classes as shown in Figure 7.

The Tier analysis per category, share a similar ratio for Tier 0 and Tier 1 engine grade for almost all vessels in different category types, except for the Bulk category that shows a greater ratio for engine grade Tier 2 and 3.

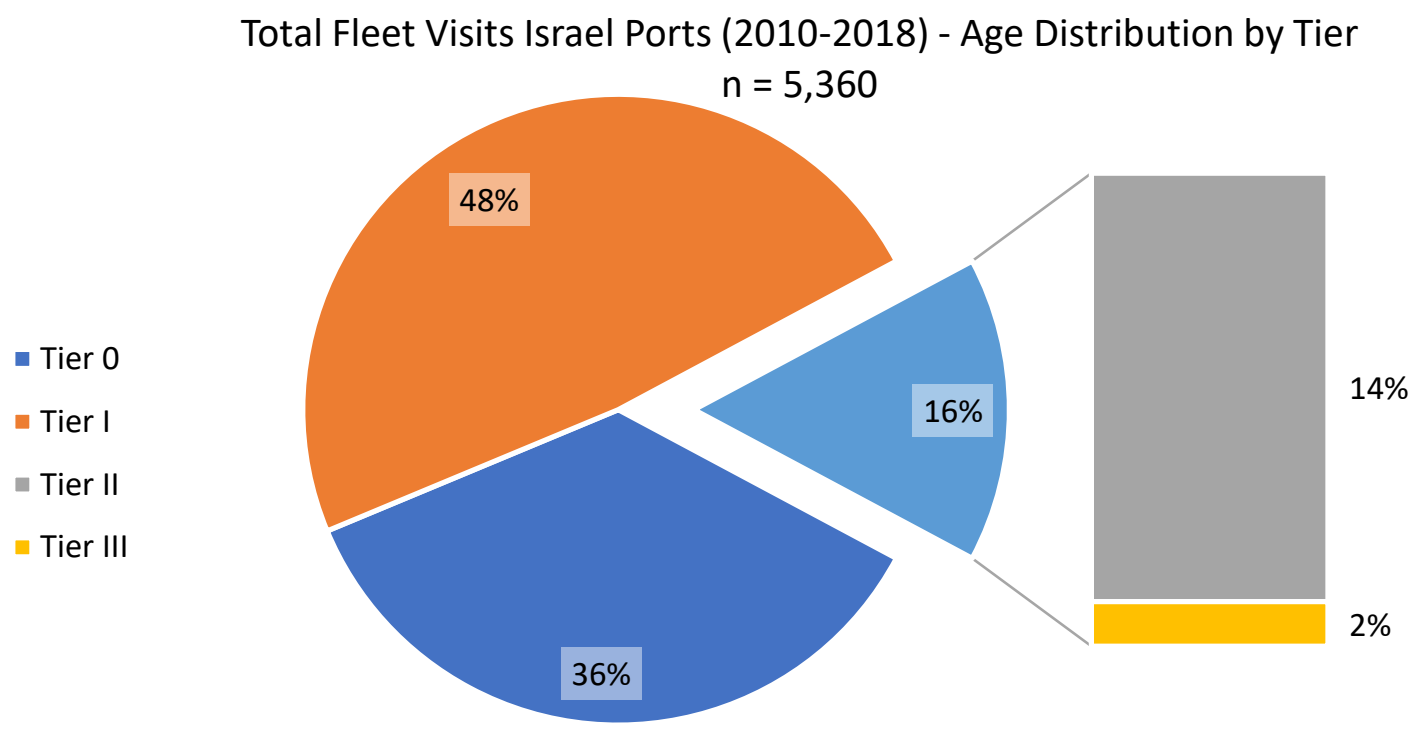

Figure 6: Fleet Visit Age Distribution by Tier Level - Israel Ports - Years 2010-2018 
Bulk Carrier - Age Distribution by Tier $\mathrm{n}=1,533$

- Tier 0

- Tier I

- Tier II

- Tier III

- Tier 0

- Tier I

- Tier II

- Tier III

RO-RO Vessels - Age Distribution by Tier $\mathrm{n}=97$

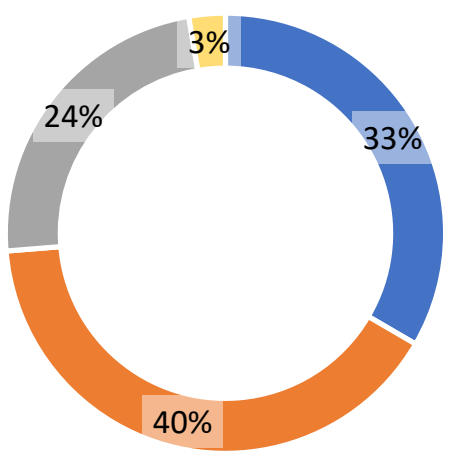

- Tier 0

- Tier I

- Tier II

$\square$ Tier III

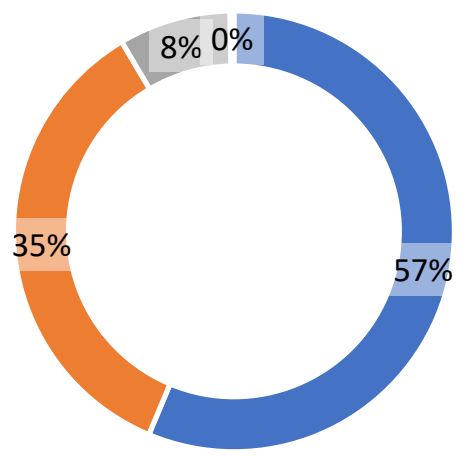

Oil / Chemical Tanker - Age Distribution by Tier $\mathrm{n}=1,099$

- Tier 0

- Tier I

$\square$ Tier II

$\square$ Tier III

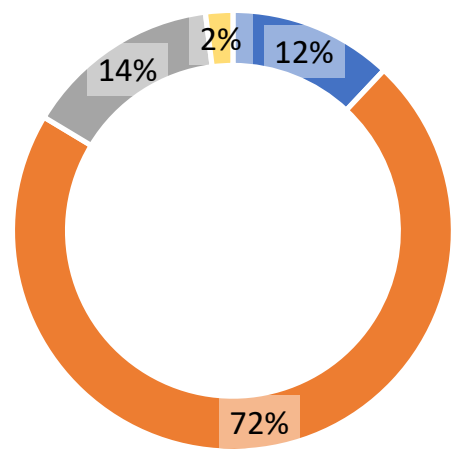

Containers Vessels - Age Distribution by Tier $\mathrm{n}=698$

- Tier 0

- Tier I

$\square$ Tier II

- Tier III
General Cargo Vessels - Age Distribution by Tier $n=1,799$

$$
\mathrm{n}=1,799
$$

er

Passenger/Cruise - Age Distribution by Tier $n=134$

- Tier 0
$\square$ Tier I
- Tier II
- Tier III
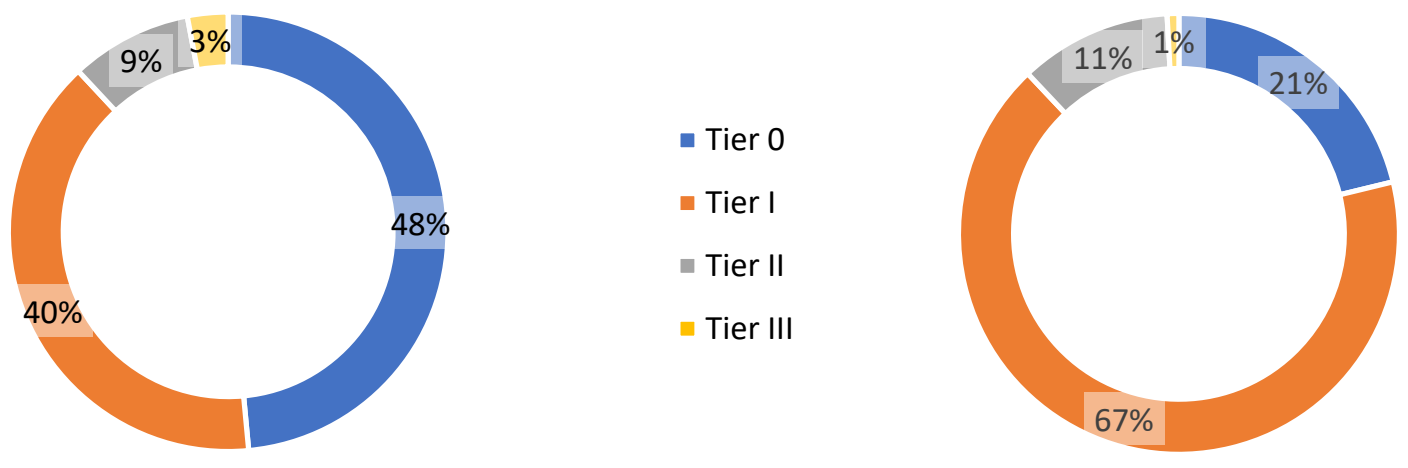

Figure 7: Vessel Visit Age Segmentize by Tier Level and Catgorey Type - Israel Ports - Years 2010-2018 


\subsection{Israel Main Ports Overviews}

The following sections present the analysis results of the Port Emission Inventory Model. To present the total emission contribution of the single vessel voyage while in port and port related area, it is necessary to include the ME, AE and boiler FC contribution to the analysis. Findings from the analysis indicate that the ME FC contribution to the total port FC, are estimated at $\sim 2.6 \%-4.8 \%$ of the total annual port FC (depending on port and year), i.e. the ME FC contribution to the Port Emission Inventory Model are not significant to the model results. Therefore, to present conservative figures, the following analysis sections were based only on AE and Boiler FC performance, as the ME FC figures were not included in the original ASP FC survey.

\subsection{Haifa Port Emission Inventory}

Findings from the Port Emission Inventory Model framework shows that Container, General cargo, and Oil Tankers dominate Haifa vessel statistics port call, as shown in Figure 8. The average annual statistics for port calls for the investigated periods is $\sim 2,600$ unique visits. Furthermore, results indicate an increase in the Dry Bulk, General cargo and Container vessels statistics port calls, in contrast to a decrease in the Chemical tanker sector. The reduction in the Chemical tanker sector can be explained due to the closing of the Haifa Chemicals plant and its ammonia tank which were the main players in this vessel sector.

The increase in Container vessels and Dry Bulk calls can be explained by the increase in transshipments`activity for Container vessels and an increase in small/Handysize bulk vessels calls, due to a market share growth of the Israel Shipyard port (i.e. the privately owned port) in the Dry Bulk and General cargo sectors. This is also reflected in an increase of FC ratio for these sectors for 2015-2018 (Figure 11). These sectors show long dwell time, due to their position in the Haifa Port pilot service operational line (i.e. last in line).

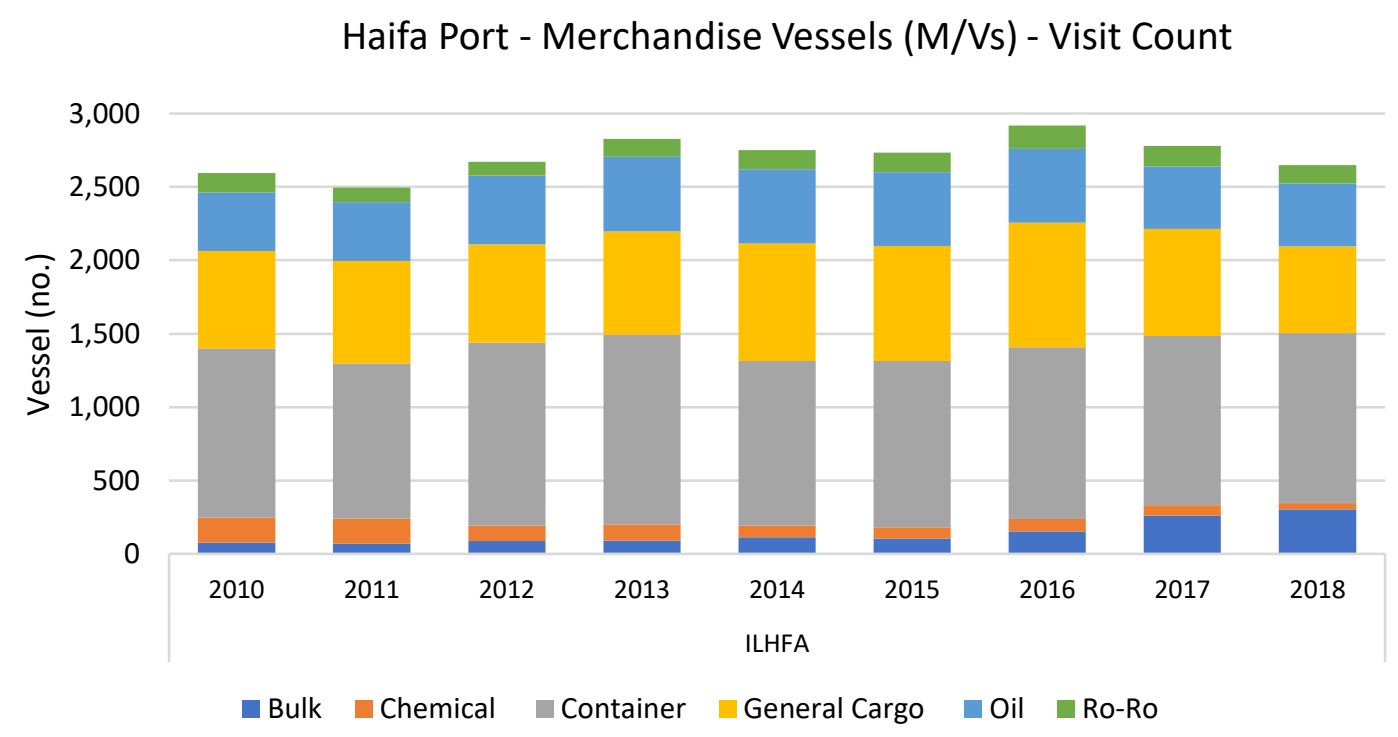

Figure 8: Haifa Port - Merchandise Vessels - Visit Count, Segmented by Vessel Category 2010-2018

Findings from the Port Emission Inventory Model framework show that the estimated total emission inventory in Haifa Bay due to vessel activity stand at an annual average of between $\sim 1,400$ to $\sim 2100$ tons of NOx and an annual average of between $\sim 1,300$ to $\sim 2,000$ tons of SOx. This can be translated to a weekly average of 27-40 tons of NOx and 25-38 tons of SOx, as shown in Figure 9. These finding are heavily dependent on vessel category type and class composition and the volume of vessels in port. 
Haifa Port - Segmented by Emissions Category Type Analysis - 2010-2018

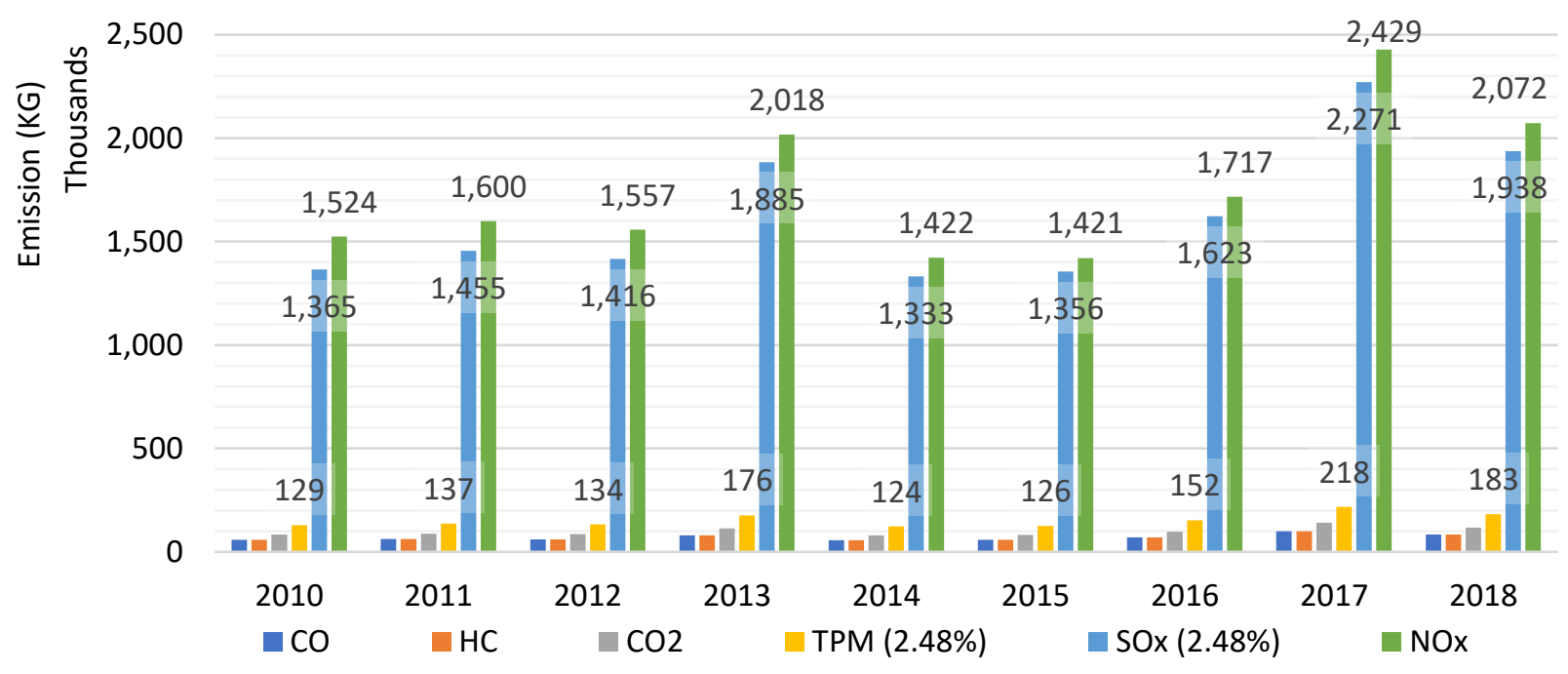

Figure 9: Cumulative Emissions at Haifa Port by Vessels - Segmented by Emission Type in Year Performance Analysis

From an analysis of nine years of historical OGV maritime traffic in port and emission inventory performance, findings from the model indicate a gradual increase in daily and yearly inventory for the period 2016-2018, compared to previous period' performance, as shown in Figure 10. This phenomenon of an increase in daily and yearly inventory can be explained by an increase in waiting time and the increase vessel presence volume in the port area. These events are a byproduct of recurrent employee sanctions. The strike actions started to take place in increasing frequency from the time of the announcement of the port structure reform in 2013 and gradually increased to a peak in 2018 as the decision date approached.

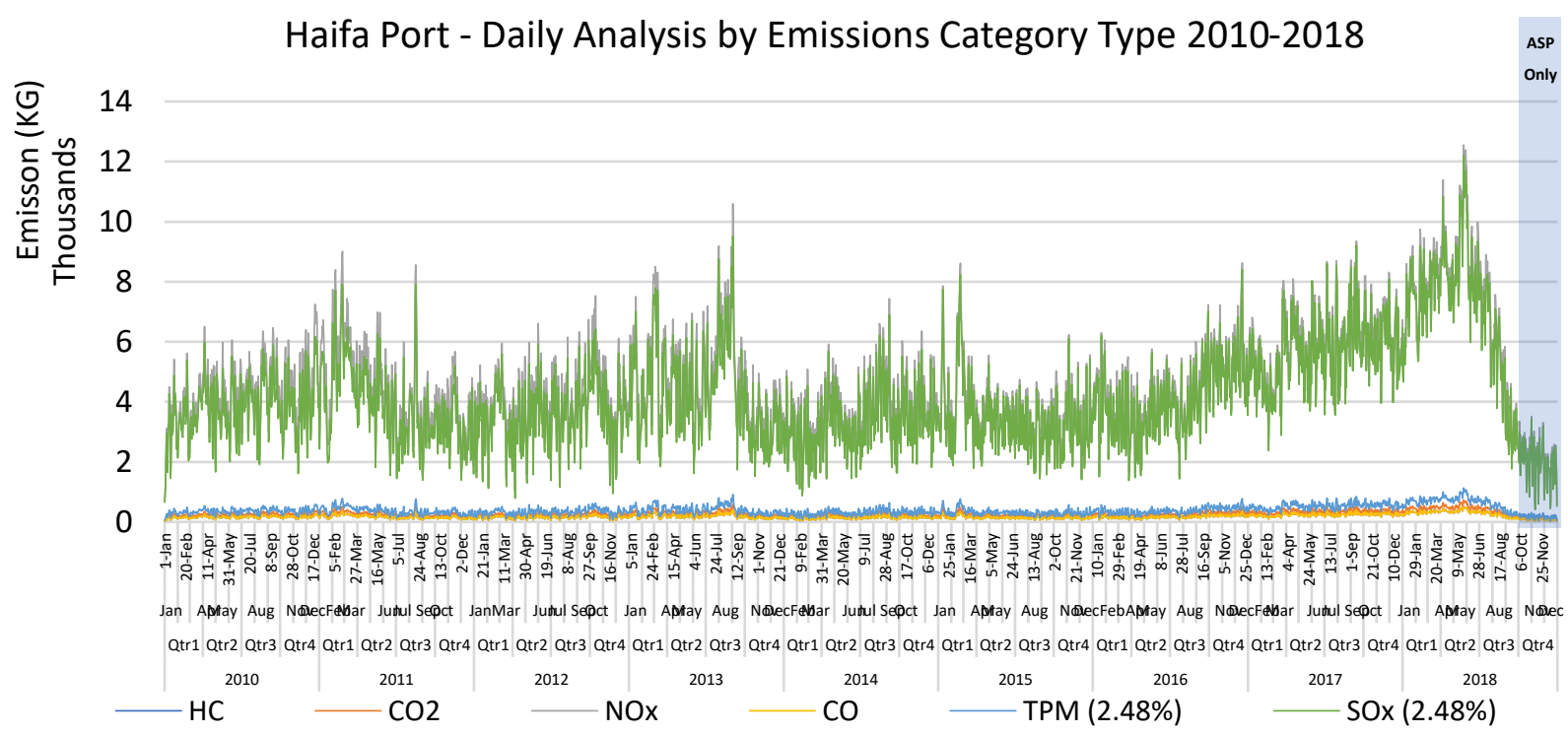

Figure 10: Cumulative Emissions at Haifa Port by Vessels - Segmented by Emission Type in Daily Performance Analysis

Changing the perspective of the model results to the FC ratio per vessel category type, as shown in Figure 11, reveals the domination of Container and Oil vessel contributions to the daily and annual level of the port emission inventory. 
Haifa Port - Fuel Consumption - 2010-2018

Ratio \& Daily Analysis by Category

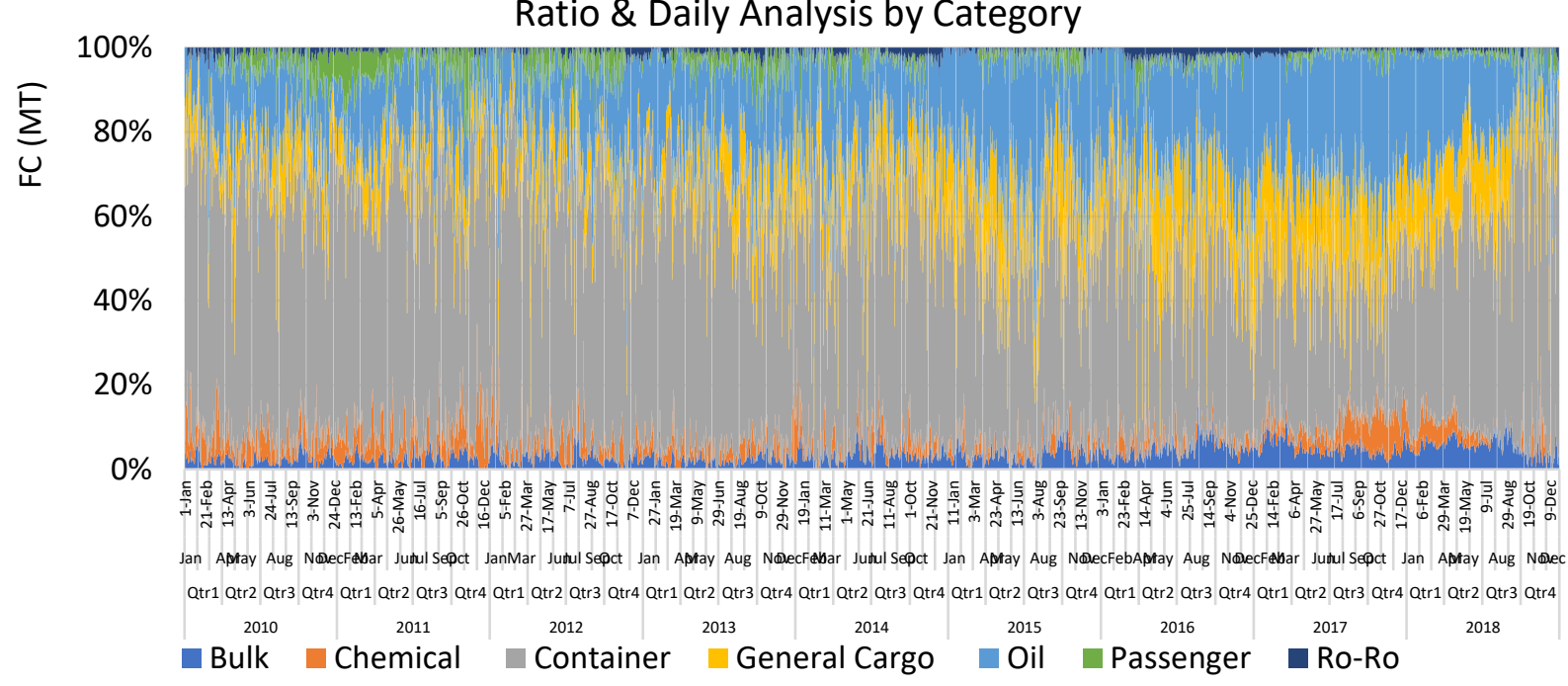

Figure 11: FC Ratio at Haifa Port - Segmented by Vessel Category in Ratio and Daily Performance Analysis

In estimating GHG or CAC emissions from vessel traffic in the port area, this study assumed that vessel FC factors for ME, AE and boiler (for maneuvering and dwell operations) for each vessel category type and class would be an important element for port emission inventory estimation. However, a high level of analysis (i.e. class) at this stage could lead to an overload of information for the common reader. Therefore, this study addressed selected sectors in maritime transportation, which serve as indicators for category type emission contribution. The following stack column charts will present the annual and daily contribution for two selected type of emission investigated NOx and SOx and for two in depth vessel catgorey and class analysis.

\subsubsection{NOx}

In terms of annual NOx emission, this study addressed Tiers: 0, 1, 2, and 3, which serve as indicators for NOx emission standards. Findings from the Port Emission Inventory Model as illustrated in Figure 12, show a shift in Tier 0 engine grade, which translates to a decrease in contribution for the years 2014-2015. This is due mainly to a change in Container vessels. However, this change was found to be temporary as from 2016 and on, there was an increase for Tier 0 engine grade compared to previous levels. This increase was due to an increase in appearance and waiting time for general cargo vessels.

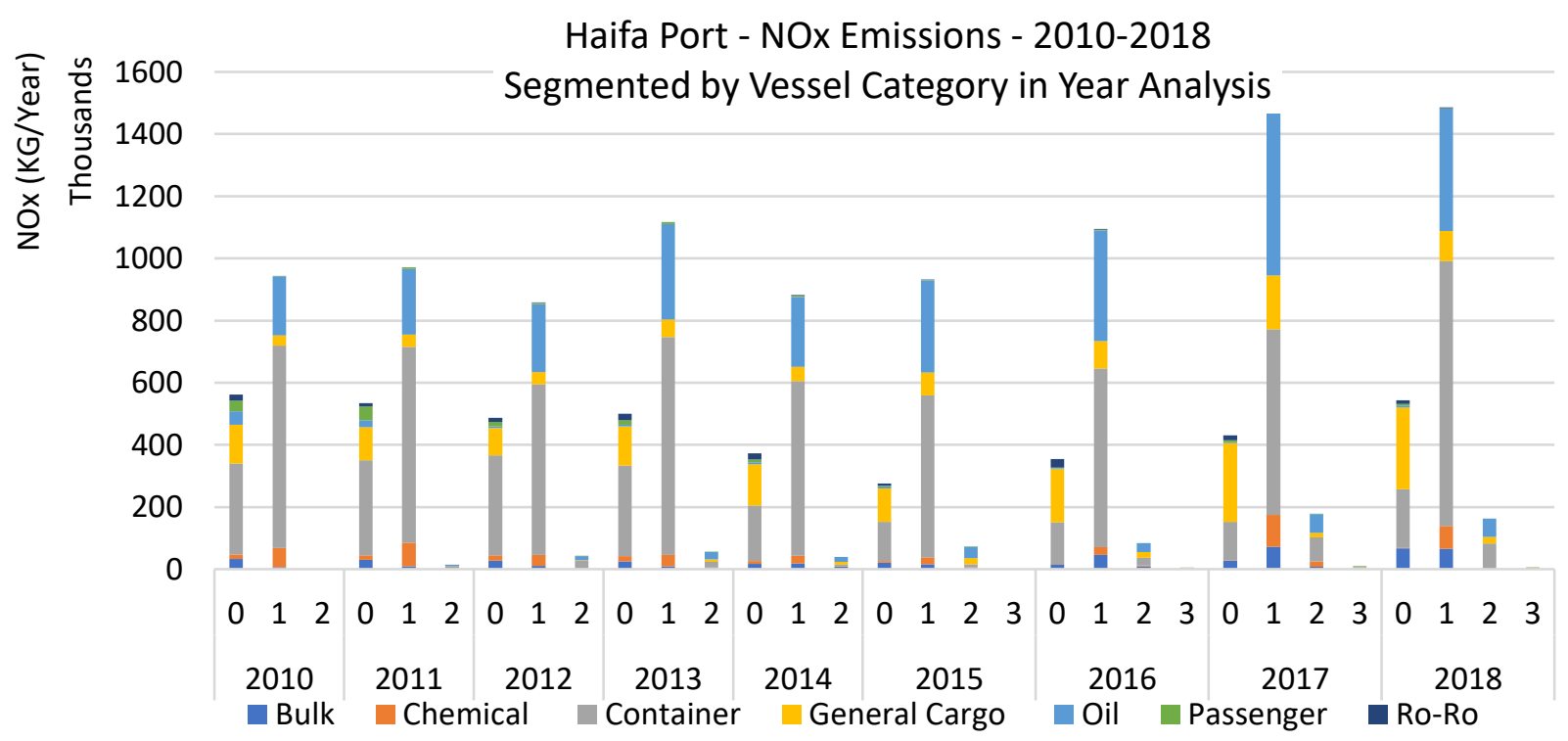

Figure 12: NOx Emissions at Haifa Port - Segmented by Engine Tier Grade and Vessel Category in Year Performance Analysis 
1 In terms of daily contribution based on Tier grade level analysis, as expected, the main contributors to daily levels is dominated by are vessels with Tier 1 2 and Tier 0 engine grades, as illustrated in Figure 13. Additional findings show that the daily average contribution of Haifa Port is estimated in the range $3 \sim 4$ to 6 tons for 2010-2016, while the daily average contribution for 2017-2018 ranges between $\sim 6$ to 10 tons, an increase of 50\% to $67 \%$ respectively. This 4 temporary increase was the effect of recurrent employee sanctions that increased the waiting time and vessel presence volume the port area during strike 5 days. Quarters Three and Four in 2018, show a drastic reduction in emission levels. These reductions were achieved only because the Port Emission 6 Inventory Model input for maritime movements in this period was based on the ASP dataset source. Nevertheless, this period was added (marked in grey) 7 to show the partial cover of ASP data on the maritime movements in ports, thus demonstrating that its perspective for vessel time at port is narrowed down 8 to operational aspects only.

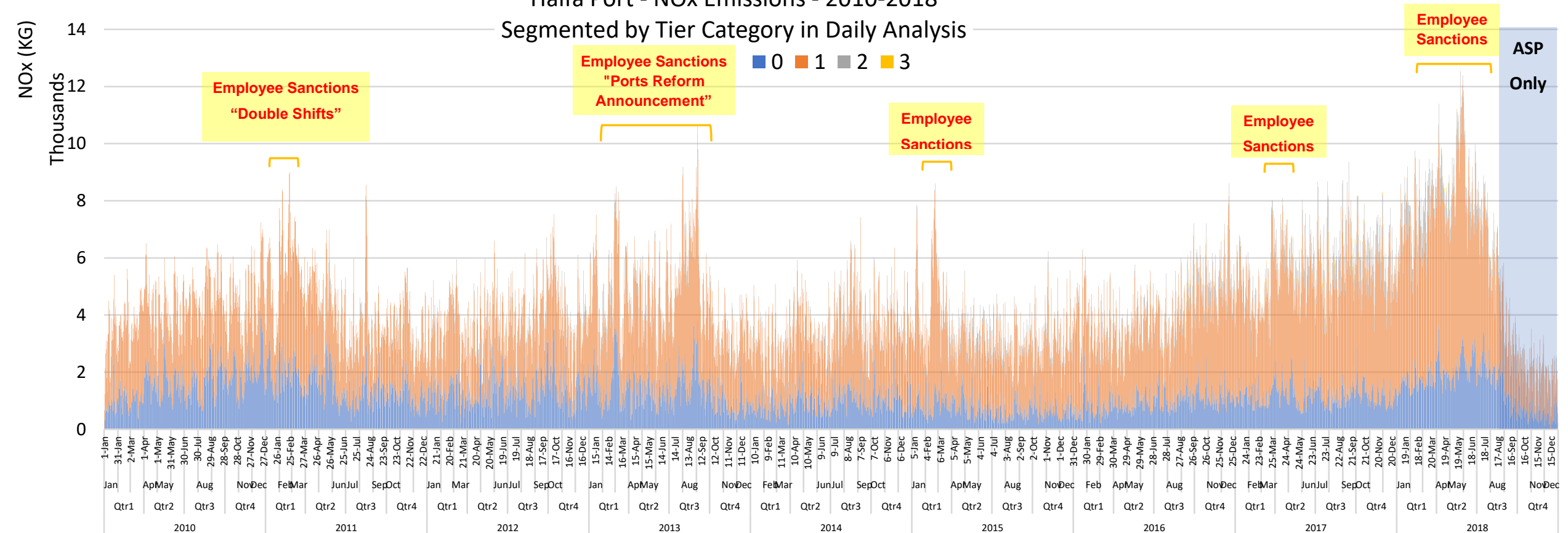

\begin{tabular}{l|l|l|l|}
2011 & 2012
\end{tabular}
2016 


\subsubsection{SOx}

2 When examining the SOX emissions, findings from the model as illustrated in Figure 14 show, 3 that the average annual SOx emissions in Haifa Port range between $\sim 1.3 \mathrm{~K}$ to $\sim 2 \mathrm{~K}$ MT for years 4 2010-2018. An average increase in the trend for the upper boundary to $\sim 2.2$ can be seen starting 5 from 2016. The main contributors were found to be container and oil vessels. This can be 6 explained by several factors: increase in frequency of vessels call from size 5K TEU and above, 7 an increase in waiting time, and an increase in frequency of employee sanctions.

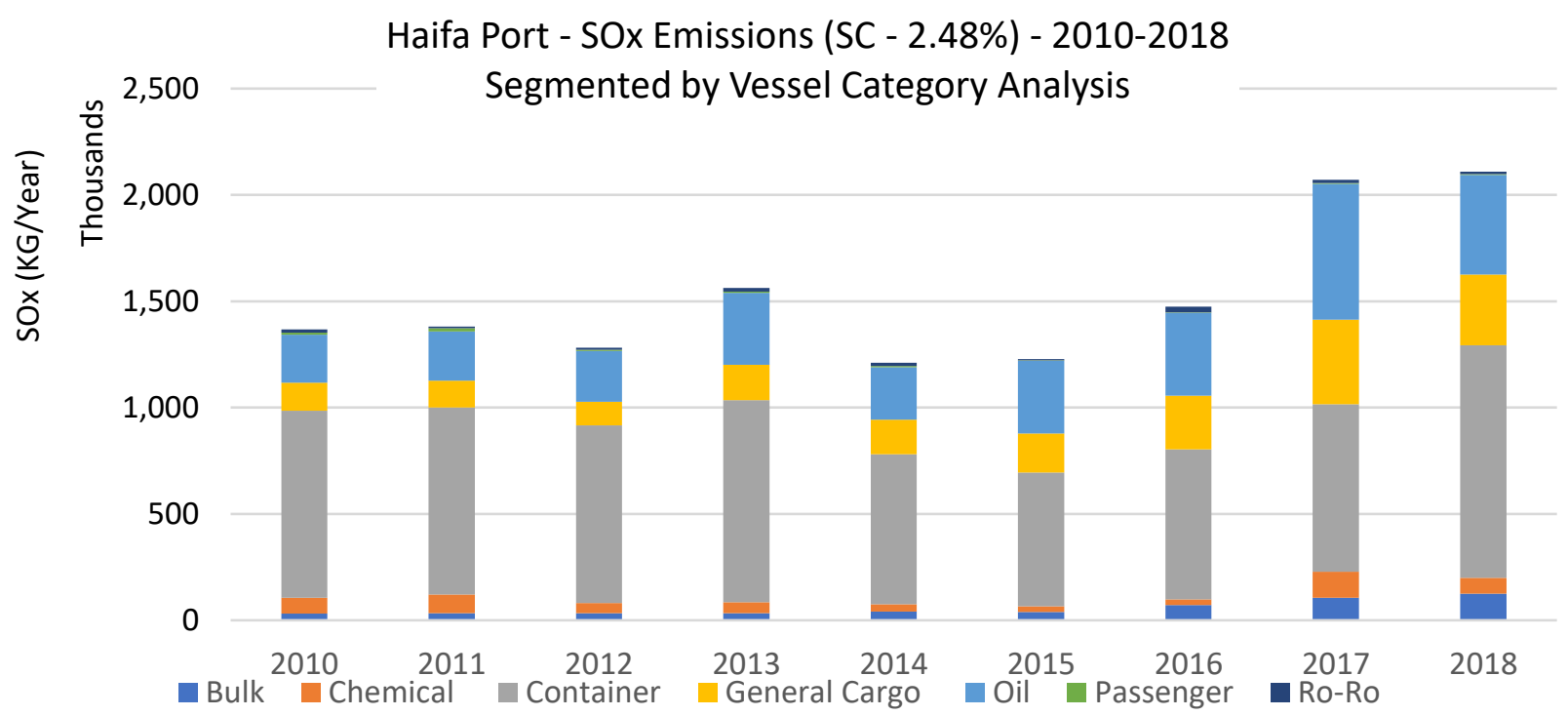


1 In terms of daily SOx emission contribution, as expected, the main daily contributors were Container and Oil tankers sector as illustrated in Figure 15. 2 Findings show that the daily average contribution of Haifa port is estimated in the range of $\sim 4$ to 5.6 tons for 2010-2016, while the daily average contribution 3 for 2017-2018 ranged between $\sim 6$ to 8.2 tons, an average increase of $\sim 50 \%$. This increase can be explained by an increase in waiting time (especially for 4 Oil/Chemical tankers and Bulk) and an increase in frequency calls of the Very Large Container Ship (VLCS), which carry 8K TEU and above. Some of 5 these vessels (i.e. Container) are known for their high FC performance while at port and are discussed in-depth in the sector classes analysis.

14

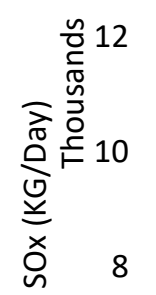

6

4

2

0

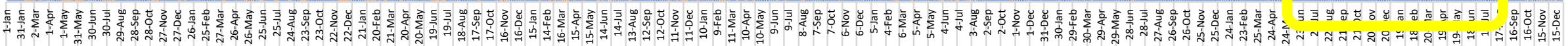

Haifa Port - SOx Emissions (SC - 2.48\%) - 2010-2018 Segmented by Vessel Catgorey in Daily Analsyis

Employee Sanctions

Port Reform Announcement

Employee

Sanctions Employee

Sanctions
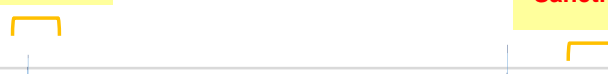

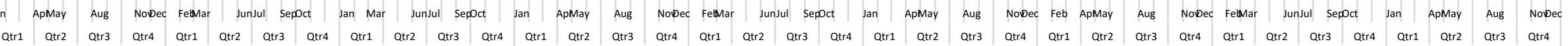

2011

Chemical
2013

Container
2014
2015
2016
2017

\section{Ro-Ro}




\section{Discussion}

The results of this study show that full bottom-up approach in emission inventory estimation that examines the single vessel's duration of stay is reliable and durable, therefore opening a new era for new tariff structure for port dues based on incorporating the single vessel emission contribution.

The results of this study show that the merchandise fleet at Israel's main ports (Haifa, Ashdod and Ashkelon) is dominated by Tier 0 (pre 2000 and unregulated) and Tier 1 (2000-2011) engine grade. Therefore, this study claims that the lack of effort for legal action or economic incentives to attract vessels with advanced Tier grade or emission reduction equipment may have created "pollution leakage" as vessels that do not comply with emission regulations in Europe or the US etc. may have found their place in Israel, middle east or other third world countries.

The results of this study show that boiler FC share in the daily port FC (i.e. full day excluding maneuvering FC contribution) is significant and cannot be overlooked as it is currently done by the IMO in all of its GHG reports. Therefore, these findings are sufficiently significant to affect the daily and yearly port emission inventory levels and consequently affect all previous IMO GHG reports findings regarding GHG and CAC emission in hotelling and berth times.

The results of this study indicate a gradual increase in daily and yearly inventory for the period 2016-2018, for Haifa port compared to previous period's performance. This phenomenon of an increase in daily and yearly inventory can be explained by several factors such as; an increase in waiting time (due recurrent employee sanctions), increase in vessel presence volume in the port area, and increase in VLCS calls. Additional results indicate that upon arrival to the port jurisdiction areas, the VLCS were very frequently found to be responsible for half of the daily total port emissions in comparison to the total existing OGV fleet in Haifa Port on that day. This analysis would be subject to change if each vessel's operational reefers (i.e. refrigerated containers) onboards were to be incorporated in this analysis (as they are expected to increase vessel FC).

These findings assure the study`s analogous claim that each port and industrial area should be examined and managed as a collection of "flue gas stacks" as illustrated in Figure 16. As this claims that due to the significantly lower height of the flue gas stacks onboard vessels compared to flue gas stacks installed in land-based plants, they may affect area air quality significantly more than those in the industrial zone. The latter are usually subject to extensive environmental emission regulations compared to vessels in port. In addition, it an important also to indicate and emphasize that OGVs usually operate in port at low speed and are densely concentrated since they are limited to anchorage circles and port berth stay. Therefore, while at port they can be considered static. In contrast to industrial areas, which may include power stations and plants that are scattered and less densely concentrated and equipped with high-altitude exhaust funnels and other equipment for emission reduction. 

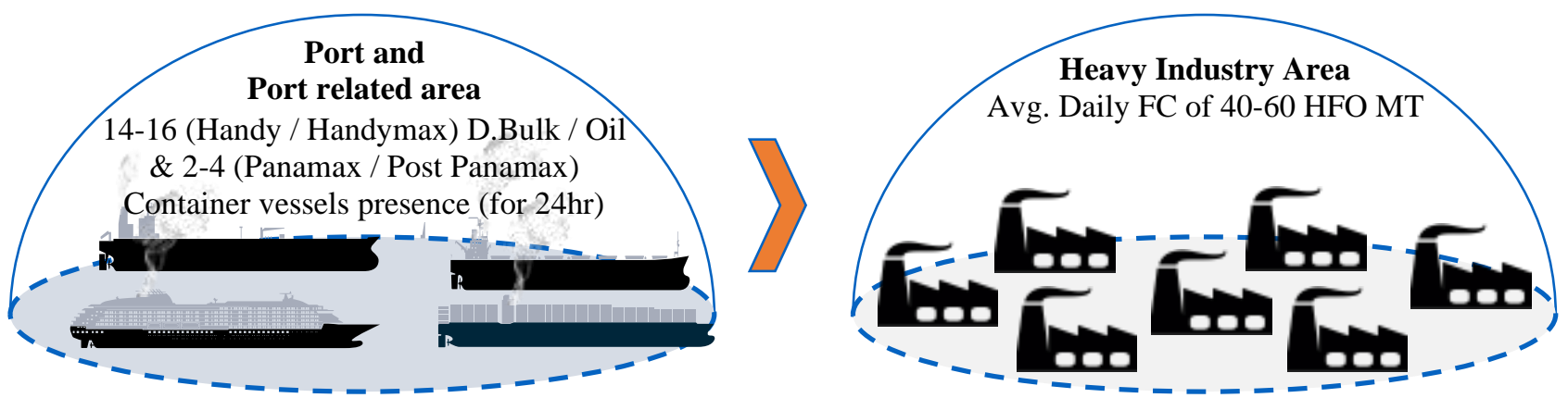

Figure 16: Emssion Inventory Level Conribution - Port \& Anchorage Circles vs. Havey Industy Area

3 Source: Own composition

4 This study recommends on an additional cost charged (selective tariff) to reflect the external social 5 cost linked to the single vessel air pollution combined with supportive technological infrastructure 6 (i.e. Ship-to-Shore Connector) and economic incentive tools (e.g. electric subsidy and/or grant for 7 installation of Alternative Marine Power - AMP) to attract or influence vessel owners to assign 8 vessels equipped with new engine Tier grades for calls at Israeli ports. 


\section{Bibliography}

2 [1] A. LEVIN, "Processing of Hydrographic Data for the Haifa Region"," Technion City, Haifa, 2012.

[2] CSA Ocean Sciences Inc., "Environmental Impact Report for Production Drilling , Production Tests , and Completion - Leviathan Field," Florida City, USA, 2016.

[3] F. M. Institute, "Maritime Boundaries Geodatabase: Maritime Boundaries and Exclusive Economic Zones (200NM).” 2016, doi: 10.14284/242.

[4] B. Elyakim. and S. Y. Van De Voorde Eddy., "Marine Environmental Emission Reduction Policy, Economic and Emission Impact," Technion - Israel Institute of Technology, 2020.

T. W. P. Smith et al., “Third IMO Greenhouse Gas Study 2014,” London, UK, 2014.

J. S. Carlton et al., "Marine Exhaust Emissions Research Programme," London, United Kingdom, 1995.

Entec, "Quantification of emissions from ships associated with ship movements between ports in the European Community," Cheshire, England, 2002.

[8] Entec, "European Commission, Directorate General Environment Service Contract on Ship Emissions: Assignment, Abatement and Market-based Instruments, Task 1 - Preliminary Assignment of Ship Emissions to European Countries," 2005.

Entec, "Service Contract on Ship Emissions: Assignment, Abatement and Market-based Instruments. Task 2 - General Report," 2005.

[10] Entec, "Ship Emissions Inventory - Mediterranean Sea, Final Report for Concawe,” 2007.

[11] Entec, "Impact Assessment for the revised Annex VI of MARPOL. Final Supporting Report for the Maritime and Coastguard Agency," 2009.

[12] S. David Cooper IVL, Tomas Gustafsson, "Methodology for calculating emissions from ships. 1. Update of emission factors,” Folkborgsvägen 1, 60176 Norrköping, Sweden, 2004.

25 [13] H. O. Kristensen, "Energy demand and exhaust gas emissions of marine engines," 2015.

26 [14] EMEP/CORINAIR, "Emission Inventory Guidebook,” 2007.

27

28

29

30

[15] A. Sarvi, Fogelholm, C. Johan, and R. Zevenhoven, "Emissions from large-scale mediumspeed diesel engines: 2. Influence of fuel type and operating mode," Fuel Process. Technol., vol. 89, no. 5, pp. 520-527, 2008, doi: 10.1016/j.fuproc.2007.10.005.

[16] EMEP/CORINAIR, “Air Pollutant Emission Inventory Guidebook," 2009. 
1 [17] EPA, "Current Methodologies in Preparing Mobile Source Port-Related Emission 2 Inventories," 2009.

3 [18] A. Kasper, S. Aufdenblatten, A. Forss, M. Mohr, and H. Burtscher, "Particulate Emissions 4 from a Low-Speed Marine Diesel Engine,” Aerosol Sci. Technol., vol. 41, no. 1, pp. 24-32, $5 \quad$ 2007, doi: 10.1080/02786820601055392.

6 [19] A. K. Ådnanes, "Maritime electrical installations and diesel electric propulsion," $A B B A S$ $7 \quad$ Mar., 2003. 